\title{
An investigation of the vitamin D Knowledge, Attitudes and Practice of UK practising doctors and nurses: the D-KAP study
}

\author{
Emily L Fallon ${ }^{1}$, Susan A Lanham-New ${ }^{1}$, Peter Williams ${ }^{1}$ and Sumantra Ray ${ }^{2}$ \\ ${ }^{1}$ Department of Nutritional Sciences, School of Biosciences \& Medicine, Faculty of Health \& Medical Sciences, \\ University of Surrey, Guildford, Surrey GU2 8HD, UK and \\ ${ }^{2}$ NNEdPro Global Centre for Nutrition and Health, Cambridge CB4 OWS, UK
}

Vitamin D deficiency, defined as plasma 25-hydroxivitamin-D $<25 \mathrm{nmol} / \mathrm{L}$, is well-documented in the UK whereby $19 \%$ aged $4-10$, $37 \% 11-18,29 \% 19-64$ and $27 \% 65+$ were recently reported as deficient ${ }^{(1)}$. Hence this is of great research interest and public health concern as vitamin D deficiency has been shown to have key implications for long-term health outcomes in humans ${ }^{(2)}$. Despite guidelines for vitamin D deficiency testing, prevention and management, many healthcare professionals (HCPs) have low self-reported vitamin D knowledge ${ }^{(3-7)}$. Most attitudes towards vitamin D appear positive ${ }^{(3-7)}$, although practices of deficiency prevention and management are limited and inconsistent ${ }^{(8)}$. However, this research is restricted to internationally practising HCPs and has not been applied to UK practising HCPs since updated vitamin D guidelines ${ }^{(9)}$. This presents concern as HCPs are responsible for health promotion and improvement, with patient nutritional status integral.

The aim of this cross-sectional study was to evaluate vitamin D knowledge, attitudes and practice of UK practising primary and secondary care HCPs. The purpose was to evidence the importance of medical and healthcare-related nutrition education for health improvement. A study-specific questionnaire was devised, validated, piloted, and distributed with multiple sampling methods. Descriptive statistics were undertaken, and backward linear regression analyses were performed to identify predictors of vitamin D knowledge and attitudes.

In total, 82 out of 147 eligible HCPs responded, comprising 23 consultant/GPs, 25 nurses, 16 specialist trainees, 10 foundation doctors and 8 core trainees, with most female (74\%), practising for $>5$ years $(68 \%)$, and without nutrition focus in their degree $(71 \%)$, or additional nutrition training $(73 \%)$. Average (SD) overall vitamin D knowledge (scale 0-100\%) was low: $49(16 \%)$. The job role consultant/GP was the only significant predictor $(\mathrm{p}=0.020)$ of superior vitamin D knowledge: $+8.863 \%$ [95\% CI $1.430-16.296]$ $\left(r^{2}=0.066\right)$. Most respondents $(94 \%)$ had positive overall attitudes towards vitamin $\mathrm{D}$, with an average score of $69 \%(12 \%)$, but no significant predictors of attitude were identified. Most (78\%) used vitamin D supplements to manage vitamin D deficiency, commonly D3 (57\%), meeting clinical recommendations. However, dosing was inconsistent and lifestyle advice regarding sunlight exposure, diet and nutrition, was found to be minimal, recommended by $50 \%$ and $49 \%$, respectively.

The present study outlines low vitamin D knowledge of UK HCPs, positive attitudes towards vitamin D and certain limitations in practices of managing vitamin D deficiency. The findings identify urgent need for HCP nutrition education to help attenuate vitamin $\mathrm{D}$ deficiency prevalence.

The author would like to thank Susan Lanham-New and Sumantra Ray for their help designing the study, and reviewing the draft manuscript; Katherine Hart, Ruan Elliot, Denise Robertson, Elaine Macaninch, Kathy Martyn and Luke Buckner for reviewing the questionnaire; Andrew Barnes for his help creating the questionnaire on Qualtrics; Timothy Eden, Rajna Golubic, and Elaine Macaninch from the Global Centre for Nutrition and Health (NNEdPro) Virtual Core for their help distributing the study questionnaire; and Peter Williams for helping to guide the statistical analyses.

1. PHE (2019) Available from: https://www.gov.uk/government/statistics/ndns-time-trend-and-income-analyses-for-years-1-to-9s

2. Rejnmark L, Bislev L, Cashman K et al. (2017) PLOS One 2, 1-39.

3. Reeder A, Jopson J \& Gray A (2012) BMC Fam Pract 13, 85-96.

4. Bonevski B, Girgis A, Magin P et al. (2012) Int J Cancer 130, 138-45.

5. Al-Amri F, Gad A, Al-Habib D et al. (2017) World J Food Sci Technol 1, 47-55.

6. AlBishi L, Prabahar K, Albalawi Y et al. (2018) Saudi Med J 39, 603-8.

7. Eckl J. (2016) New York: Daemen College 87 p.

8. Epling J, Mader E, Roseamelia C et al. (2015) Qual Health Res 25, 1005-12.

9. SACN (2016) Available from: https://www.gov.uk/government/publications/sacn-vitamin-d-and-health-report\%0Ahttps://www.gov.uk/government/uploads/system/uploads/attachment_data/file/537616/SACN_Vitamin_D_and_Health_report.pdf 